\title{
Hacettepe Üniversitesindeki Engelli Çalışanların Karşılaştıkları Psikolojik Şiddet Davranışları (Mobbing) ve Bu Davranışların Etkileri
}

\author{
Özge Buket Cesim ${ }^{1}$, Özgür Şanl1 ${ }^{1}$, Burcu Semin Akel ${ }^{1}$ \\ ${ }^{1}$ Hacettepe Üniversitesi, Sağlık Bilimleri Fakültesi, Ergoterapi Bölümü
}

\begin{abstract}
Özet
Amaç: Mobbing; işyerlerinde bir veya birden fazla kişiye yönelik, belirli bir süre sistemli bir biçimde devam eden, yıldırma veya işten uzaklaştırmayı amaçlayan, insanların mesleki statülerine, kişilik değerlerine, sosyal ilișkilerine veya sağlıklarına zarar veren; kötü niyetli, kasıtlı olumsuz davranıșlarda bulunulması olarak belirtilmektedir. $\mathrm{Bu}$ çalışma Hacettepe Üniversitesi'nde çalışan engelli personelin iş yerinde karşılaştı̆̆ psikolojik şiddet davranışlarını ve bu davranışların engelli çalışanlar üzerindeki etkilerini belirlemek amacıyla gerçekleş̧irilmiştir.

Gereç ve Yöntem: Araştırmaya kamuda çalışan 30 engelli birey katıldı. Değerlendirme Nisan-Mayıs 2014 tarihleri arasında üç kısımdan meydana gelen anket ile yapıldı. İlk kısımda kişilerin demografik bilgileri alındı. İkinci kısımda kişilere maruz kaldıkları psikolojik şiddet davranışları, üçüncü kısımda ise maruz kaldıkları şiddet davranışlarının sosyal, fizyolojik ve psikolojik etkileri sorgulandı.

Bulgular: Çalışmaya dahil olan engelli bireylerin en fazla "konuşurken sık s1k sözlerinin kesilmesine" ve "başkalarının yanında küçük düşürücü davranılmasına" maruz kaldıkları belirlendi. Uygulanan mobbing davranışı sonrası etki en fazla "kendimi stresli ve yorgun hissediyorum" şeklinde belirtildi. Bu etkiler ve davranışlar bireylerin \%10-16' sı tarafindan ifade edildi.

Sonuç: Hacettepe Üniversitesi' nde çalışan engelli kişilerin büyük bir kısmının mobbing davranıșıyla karşılaşmadığı ancak az bir kısmının ise kasten mobbing davranışları yaşadığı belirlenmiştir. Engelli çalışanlarda mobbing etkilerini minimuma indirebilecek çalışmalar yapılmasının mobbing davranışlarını önlemeye ve engelli bireylerin çalışma ortamlarının iyileştirilmesine katkıda bulunacağına inanmaktayız.
\end{abstract}

Anahtar kelimeler: Engelli, çalışan, psikolojik, şiddet

Sorumlu Yazar: Özge Buket Cesim. Hacettepe Üniversitesi, Sağlık Bilimleri Fakültesi, Ergoterapi Bölümü, Ankara. 031230525 60. obuketcesim@hacettepe.edu.tr

Gönderim Tarihi: 18.01 .2018

Kabul Tarihi: 26.04 .2018 


\title{
Psychological Violence Behaviors Experienced by Disabled Employees at Hacettepe University (Mobbing) and the Effects of These Behaviors
}

\author{
Özge Buket Cesim ${ }^{1}$, Özgür Şanlı ${ }^{1}$, Burcu Semin Akel ${ }^{1}$ \\ ${ }^{1}$ Hacettepe University, Faculty of Health Sciences, Occupational Therapy Department
}

\begin{abstract}
Objective: Mobbing reflects as a detaining or intimidating one or more persons in a workplace, which continues in a systematic manner for a certain period of time, harms people's professional status, personality values, social relations or health; malicious, deliberate negative behavior. This study was conducted to determine the psychological violence behaviors of disabled personnel working at Hacettepe University in the workplace and the effects of these behaviors on disabled employees.

Material and Methods: 30 disabled people who work in the public participated to the research. The evaluation was conducted between April and May 2014 with a three-part questionnaire. In the first part demographic information of the participants was obtained. In the second part, the psychological violence behaviors they were exposed and in the third part the social, physiological and psychological effects of the violent behaviors they were exposed were questioned.

Results: People with disabilities who were included in the study were found to have been most exposed "to interrupt while talking frequently" and "to be humiliated by others". The effect after the applied mobbing behavior was stated as "I feel stressed and tired myself". These effects and behaviors were expressed by $10-16 \%$ of individuals.

Conclusion: It has been determined that most of the disabled people working at Hacettepe University have not experienced mobbing behavior but a few have experienced deliberately mobbing behavior. We believe that efforts to minimize the effects of mobbing in disabled workers will help prevent mobbing behavior and improve the working environment of disabled people.
\end{abstract}

Keywords: Disabled, working, psychological, violence.

Corresponding Author: Özge Buket Cesim. Hacettepe University, Faculty of Health Sciences, Occupational Therapy Department. Ankara. 031230525 60. obuketcesim@hacettepe.edu.tr

Submission Date: 18.01.2018

Acception Date: 26.04.2018 


\section{Giriş}

İş yerinde yaşanan psikolojik şiddet, diğer kullanımıyla mobbing kelimesi ilk olarak Heinz Leymann tarafından kullanılmıştır ve iş yerlerinde görülen bu davranışların bir tür "iş yeri terörü" olduğunu söylemiştir. Bu bağlamda iş yeri terörünü "bir kişinin ya da bir topluluğun, bir kişiye sürekli olarak yönelttikleri etik olmayan iletişim ile düşmancıl davranışlarda bulunması" olarak tanımlamıştır (Chappell, Di Martino, 2000; Leymann, 1990). Türkçe'de "mobbing" kelimesi, işte yıldırma, sindirme, bastırma, psikolojik şiddet gibi anlamlara gelmekle beraber, ülkemizde iş yerinde meydana gelen şiddet konusunda bazen sadece "mobbing" kelimesinin kullanımına rastlanmaktadır (Davenport, Schwartz ve Elliott, 2003; Tutar, 2014; Tınaz, 2016). Psikolojik şiddet eylemleri, Uluslararası Çalışma Örgütü’ne göre işyerlerinde 2000 'li ylllarda meydana gelen en ciddi problemdir. Sürekli uygulanan ve uzun bir zaman diliminde devam ettirilen bu olaylar, iş yerindeki stres türleri içerisinde en dikkate alınması gerekendir (Di Martino, Hoel ve Cooper, 2013).

Leymann iş yerinde psikolojik şiddet sürecinde 5 faz belirtmiştir. İlk faz tanılama fazıdır, bu fazda kişi asi veya psikolojik sorunları olan biri şeklinde etiketlenir. Anlaşmazlık fazında, ciddi olan bir sorun vaya anlaşmazlık yaşanır (Leymann, 1996). Henüz mobbing olmasa da mobbing davranışlarına doğru gidebilir. Saldırganlık fazında, saldırgan tutumlar ve davranışlar başlar, mobbing dinamiklerinin ortaya çıktığını gösterir. Kurumsal kuvvet fazında kurumdaki yönetimin önyargısı ve taraflı olan tutumu bu olumsuz davranışları arttııır. Kişi sadece mobbingi uygulayanlar ile değil, kurumsal kuvvetle de savaşmak zorunda kalır. İşini kaybetme fazında kişinin yaşadığı psikolojik şiddet ve gerginlik, posttravmatik stres bozukluğunu tetikleyebilir, bu aşamada ya kişi işten atılabilir ya da kişi işi bırakabilir. Ancak bu fazda kişi işinden ayrılırsa da yaşadığı psikolojik baskının etkisinden kurtulamaz (Tutar, 2014; Leymann, 1996; Leymann ve Gustafsson, 1996).

Mobbing mağdurlarının mental sağlığının büyük ölçüde etkilendiği, ciddi psikolojik ve psikososyal sorunlar yaşadığı literatürde belirtilmektedir (Leymann, Gustafsson, 1996; Figueiredo- Ferraz ve diğ., 2012). Uzun bir zaman devam eden psikolojik şiddet, kişinin fizyolojik, psikolojik ve sosyal dengesini kötü yönde etkiler (Einarsen, 1996; Salin, 2003; Björkqvist, 2001; Nielsen ve diğ., 2015). Literatürde iş yerinde sürekli mobbinge maruz kalan kişilerin benlik saygılarının azaldığı, kaygı, depresyon ve öfke belirtileri gösterdiği belirtilmektedir (Einarsen, 1996; Quine, 1999; Bilgel, Aytaç ve Bayram, 2006; A. Yıldırım, D. Yıldırım, 2007). Birçok mobbing mağdurunun travma sonrası stres bozukluğu yaşadığı ve bazılarının intihar girişiminde bulunduğu da söylenmektedir (Leymann, 1990; Bilgel, Aytaç \& 
Bayram, 2006; Fox, Stallworth, 2005; Stebing ve diğ., 2004). İş yerinde psikolojik şiddet yaşayan kişiler, üzerlerindeki baskıyı ve zulmü ortadan kaldırmak için hastalık raporu almaya başlar, kendi istekleriyle ya da mecburi olarak istifa edebilirler, işten atılabilir veya erkenden emekli olma yönünde baskıya maruz kalabilirler (Davenport, Schwartz ve Elliott, 2003; Tinaz, 2006; Einarsen, Matthiesen ve Skogstad, 1998). Bu dönemde mesleğini ve sağglı̆̆ını da kaybeden kişiler finansal, bedensel ve emosyonel olarak etkilenmektedir (Einarsen, 1996; Björkqvist, 2001; Fox ve Stallworth, 2005; Björkqvist, Österman ve Hjelt-Back, 1994).

Engelli çalışanlar, diğer tüm çalışan bireylere oranla daha fazla ve daha sık süre ile mobbing yaşamaktadırlar. Mobbing yalnızca özel iş alanlarıyla sınırlı kalmamakta ve çokça kamu kurum ve kuruluşunda da bu türden durumlara yoğun bir şekilde rastlanmaktadır. Kendileriyle aynı konumda çalışan iş arkadaşları ya da kendilerinden üst seviyede bulunan amirler engelli çalışanlara psikolojik şiddet gösterebilmektedirler. Mobbing davranışları; engelli çalışanlara iş vermeme, yaptıkları işi küçük görme, kendi isteği dışında erken emekliliğe zorlama gibi değişik şekillerde olabilmektedir (Yılmaz, 2011). Çalışmamızın amacı Hacettepe Üniversitesi'nde çalışan engelli personelin iş yerinde karşılaştığı psikolojik şiddet davranışlarını ve bu davranışların engelli çalışanlar üzerindeki etkilerini belirlemektir.

\section{Gereç ve Yöntem}

\section{Örneklem}

Çalışmaya Hacettepe Üniversitesi'nde engelli olarak çalışan gönüllü bireylerin dahil edilmesi planlandı. Çalışma Nisan-Mayıs 2014 tarihleri arasında yapıldı. Hacettepe Üniversitesi Personel Daire Başkanlığı'ndan engelli çalışanların listesi alındı. Listedeki 111 kişiden 61 kişi ile iletişim bilgisi eksikliğinden iletişime geçilemedi, kalan 50 kişiden 10' unun engeli yoktu, diğer 10 kişi ise çalışmaya katılmak istemediğini belirtti. Toplamda 30 kişiye ulaşıld1.

Çalışmaya dahil edilme kriterleri; 18-65 yaş arasında olmak, Hacettepe Üniversitesi'nde çalışıyor olmak, ortopedik, işitme veya görme engelli olmak ve çalışmaya katılmaya gönüllü olmak olarak belirlendi. Çalışmadan hariç tutulma kriteri ise; konuşma problem olmak olarak belirlendi. Çalışmada Helsinki Deklarasyonu esas alındı. Çalışma öncesinde tüm kişilere çalışma ve mobbing hakkında bilgi verildi ve aydınlatılmış onam formu imzalatıldı. Çalışma kişilerin iş yerlerindeki çalışma ortamlarında, diğer çalışanlar ve yöneticilerden bağımsız bir ortamda ikinci yazar tarafından kişilerle yüz yüze görüşme yöntemiyle yapıldı. 


\section{Veri Toplama Araçları}

Veri toplamada, Mobbing ile Mücadele Derneği tarafından genel popülasyonun mobbing davranışlarına maruz kalma durumunu belirlemek amacıyla oluşturulan anket formu kullanıldı. Bu anket üç bölümden oluşup birinci bölümde katılımcıların demografik bilgileri (cinsiyet, yaş, eğitim, meslek), ikinci bölümde işte görülen psikolojik şiddet davranışları, üçüncü bölümde şiddet davranışları sonucu yaşanan fizyolojik, psikolojik ve genel sağlık ile ilgili değişimler sorgulanmaktadır.

Formun ikinci bölümünde işte görülen psikolojik şiddet davranışları dört başlık altında ele alındı ve bireylerin işte izolasyonu, statüye saldırı, kişiliğe yapılan saldırı ve doğrudan maruz kalınan olumsuz yöndeki davranışlar belirtildi. Davranışların yaşanma sıklığını ortaya koymada, 0=hiç karşılaşmadım, 1=bir kez karşılaştım, 2=birkaç kez, 3=bazen, 4=sık sık, 5=her zaman karşılaşıyorum şeklinde numaralandırılarak, 6’lı likert yöntemi kullanıldı.

Üçüncü bölümde işte yaşanan psikolojik şiddet davranışlarının kişiler üzerindeki etkileri, bu davranışa maruz kalındığında karşılaşılan psikolojik, fizyolojik ve çalışma performansı ile ilgili durumlar değerlendirildi. Engelli çalışanların işte yaşadıkları psikolojik şiddet davranışlarının psikolojik ve sağlık statüleri ve çalışma performansı üzerinde etkisi evet $=1$, hayır=2 şeklinde değerlendirilerek formda işaretlemeleri istendi.

İstatistiksel analiz SPSS 17 paket programı ile gerçekleştirildi. Verileri analiz ederken tanımlayıcı istatistikler (frekans, yüzde ve standart sapma) kullanıldı.

\section{Bulgular}

Araştırmaya katılan engelli çalışanların (n=30, yaş aralı̆̆ı 22-54) 6’sı (\%20) kadın,

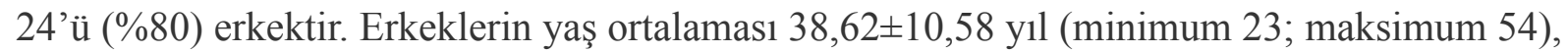
kadınların yaş ortalaması 36,16 $\pm 9,10$ (minimum 22; maksimum 47) yıldır. Katılımcıların \%43,3'ü ilköğretim, \%33,3'ü lise \%23,3’ü lisans mezunudur. Araştırmaya katılanların büyük bir kısmı $(\% 46,7)$ tekniker olarak çalışmakta olup, memur olarak çalışanlar $(\% 36,7)$, hasta bakıcılar $(\% 6,7)$, sağlık çalışanı $(\% 3,3)$, bilgisayar işletmeni $(\% 3,3)$, hizmetli $(\% 3,3)$ gibi farklı alanlarda çalışmakta olan personellerden oluşmaktadır.

Tablo 1'de üniversitede çalışan engelli personelin karşılaştıkları psikolojik şiddet davranışları ve karşılaşma yüzdeleri belirtilmiştir. Üniversitede çalışan engelli çalışanların en fazla karşılaştıkları davranışlar "konuşurken sık sık sözünüzün kesilmesi” ve "başkalarının yanında küçük düşürücü davranılması” $(\% 13,4)$, “yapılan iş ve işin sonuçları ile ilgili sürekli kusur/hata bulunması" (\%13,3), "kapasitenin üstünde işlerden sorumlu tutulma” $(\% 13,2)$ 
olduğu gibi hiç uygulanmayan davranış tipi olarak "fiziksel şiddet uygulanması" yer almaktadır.

Tablo 2'de psikolojik şiddet davranışının etkileri belirtilmiştir. Uygulanan mobbing davranışı sonrası etkiler en fazla "kendimi stresli ve yorgun hissediyorum" (\%16,7), "bana yapılan düşmanca davranışları hatırladığımda şiddetli üzüntü duyuyorum” (\%10), "yapılan davranışları tekrar tekrar hatırlıyorum/yaşıyorum" (\%10), "kendimi yalnız hissediyorum" (\%10), "iş dışındaki hayatım bundan olumsuz etkileniyor" (\%10), "bir işe konsantre olmada güçlük yaşıyorum” (\%10) olarak belirtilmiştir.

Tablo 1. Hacettepe Üniversitesi'nde çalışan engelli personelin belirttiği "Psikolojik Şiddet Davranışları" $(\mathrm{n}=30)$

\begin{tabular}{|c|c|c|c|c|c|c|}
\hline & 0 & 1 & 2 & 3 & 4 & $5^{*}$ \\
\hline \multicolumn{7}{|l|}{ Bireylerin işte izolasyonu } \\
\hline $\begin{array}{l}\text { 1. Bulunduğunuz ortamda görmezden } \\
\text { gelinerek, yokmuşsunuz gibi } \\
\text { davranılması }\end{array}$ & 93,3 & - & - & - & - & 6,7 \\
\hline $\begin{array}{l}\text { 2. Görüşme ve konuşma isteğinize yanıt } \\
\text { alamama }\end{array}$ & 96,7 & - & - & - & - & 3,3 \\
\hline $\begin{array}{l}\text { 3. Sorumluluğunuzda olan işlerin sizden } \\
\text { alınarak, sizden daha düşük pozisyonda } \\
\text { kișilere verilmesi }\end{array}$ & 96,7 & - & - & - & - & 3,3 \\
\hline $\begin{array}{l}\text { 4. Kendiniz göstermenize firsat } \\
\text { verilmemesi }\end{array}$ & 93,3 & - & 3,3 & - & - & 3,3 \\
\hline $\begin{array}{l}\text { 5. Düzenlenen sosyal toplantılardan } \\
\text { haberdar edilmeme }\end{array}$ & 93,3 & - & - & - & - & 6,7 \\
\hline $\begin{array}{l}\text { 6. Verdiğiniz karar ve önerilerin } \\
\text { eleștirilerek reddedilmesi }\end{array}$ & 96,7 & - & - & - & 3,3 & - \\
\hline $\begin{array}{l}\text { 7. Sizden daha düşük pozisyonda kişiler } \\
\text { tarafından denetlenmeniz }\end{array}$ & 96,7 & - & - & - & 3,3 & - \\
\hline $\begin{array}{l}\text { 8. Konuşurken s1k s1k sözünüzün } \\
\text { kesilmesi }\end{array}$ & 86,7 & - & 6,7 & - & - & 6,7 \\
\hline $\begin{array}{l}\text { 9. İșten ayrılmanız ya da yer } \\
\text { değiştirmeniz için bask1 yapılması }\end{array}$ & 96,7 & - & - & - & - & 3,3 \\
\hline $\begin{array}{l}\text { 10. Gönderdiğiniz elektronik posta ve } \\
\text { telefonlara yanıt verilmemesi }\end{array}$ & 96,7 & - & - & - & - & 3,3 \\
\hline $\begin{array}{l}\text { 11. İşiniz için gerekli olan bilgi, doküman } \\
\text { ve materyallerin sizden saklanması }\end{array}$ & 96,7 & - & - & - & - & 3,3 \\
\hline \multicolumn{7}{|l|}{ Mesleki statüye saldırı } \\
\hline $\begin{array}{l}\text { 12. Yaptı̆̆ınız iş ve işin sonuçları ile ilgili } \\
\text { sürekli kusur/hata bulunması }\end{array}$ & 86,7 & 3,3 & 3,3 & 3,3 & - & 3,3 \\
\hline $\begin{array}{l}\text { 13. Kapasitenizin üstünde işlerden sorumlu } \\
\text { tutulmanız }\end{array}$ & 86,7 & 3,3 & - & - & 3,3 & 3,3 \\
\hline
\end{tabular}




\begin{tabular}{|c|c|c|c|c|c|c|}
\hline $\begin{array}{l}\text { 14. Ortak yapılan işlerin olumsuz } \\
\text { sonuçlarından yalnızca sizin sorumlu } \\
\text { tutulmanız }\end{array}$ & 93,3 & - & - & - & - & 6,7 \\
\hline $\begin{array}{l}\text { 15. Sorumlu olmadığınız konularda } \\
\text { suçlanmanız }\end{array}$ & 90 & 3,3 & - & - & $3-3$ & 3,3 \\
\hline $\begin{array}{l}\text { 16. Yaptığınız her işte mesleki } \\
\text { yeterliliğinizin sorgulanması }\end{array}$ & 93,3 & 3,3 & - & - & - & 3,3 \\
\hline $\begin{array}{l}\text { 17. Yaptığınız işin değersiz ve önemsiz } \\
\text { görülmesi }\end{array}$ & 90 & 3,3 & - & - & 6,7 & - \\
\hline $\begin{array}{l}\text { 18. Performansınızla ilgili sürekli olumsuz } \\
\text { değerlendirmeler yapılması }\end{array}$ & 93,3 & - & 3,3 & 3,3 & - & 3,3 \\
\hline $\begin{array}{l}\text { 19. Sizin ve yaptığınız işin hissettirilmeden } \\
\text { (dolaylı) kontrol edilmesi }\end{array}$ & 90 & - & 3,3 & 3,3 & - & 3,3 \\
\hline $\begin{array}{l}\text { 20. Özgüveninizi olumsuz etkileyecek bir } \\
\text { iş yapmaya zorlanılmanız }\end{array}$ & 96,7 & - & - & - & - & 3,3 \\
\hline \multicolumn{7}{|l|}{ Kişiliğe saldırı } \\
\hline $\begin{array}{l}\text { 21. Masaya yumruk vurulması gibi } \\
\text { davranışlarla karşılaşma }\end{array}$ & 93,3 & 3,3 & - & - & 3,3 & - \\
\hline $\begin{array}{l}\text { 22. Sizinle ilgili asılsız söylemlerde } \\
\text { bulunulması }\end{array}$ & 93,3 & 3,3 & - & 3,3 & - & - \\
\hline 23. Sözlü tehdit edilme & 96,7 & - & - & - & - & 3,3 \\
\hline $\begin{array}{l}\text { 24. Başkalarının yanında sizinle aşağılayıcı } \\
\text { ve onu kırıcı konuşulması }\end{array}$ & 90 & 10 & - & - & - & 3,3 \\
\hline $\begin{array}{l}\text { 25. Başkalarının yanında size küçük } \\
\text { düşürücü davranılması (beden dili } \\
\text { kullanılması) }\end{array}$ & 86,7 & 6,7 & 6,7 & - & - & - \\
\hline $\begin{array}{l}\text { 26. Özel yaşantınızla ilgili asılsız } \\
\text { söylentiler çıkarılması }\end{array}$ & 96,7 & 3,3 & - & - & - & - \\
\hline $\begin{array}{l}\text { 27. Ruh sağlığınızın yerinde olmadığının } \\
\text { ima edilmesi }\end{array}$ & 96,7 & 3,3 & - & - & - & - \\
\hline $\begin{array}{l}\text { 28. Dürüstlüğünüzün ve güvenilirliğinizin } \\
\text { sorgulanması }\end{array}$ & 90 & 3,3 & - & 3,3 & 3,3 & - \\
\hline $\begin{array}{l}\text { 29. Sizinle ilgili haksız gerekçelerle } \\
\text { yazışmalar yapılması/rapor tutulması }\end{array}$ & 96,7 & - & - & - & - & 3,3 \\
\hline \multicolumn{7}{|l|}{ Doğrudan yapılan olumsuz davranışlar } \\
\hline 30. Fiziksel şiddet uygulanması & 100 & - & - & - & - & 3,3 \\
\hline 31. Şahsi eşyalarınıza zarar verilmesi & 96,7 & 3,3 & - & - & - & - \\
\hline $\begin{array}{l}\text { 32. Bir ortama girdiğinizde, bulunduğunuz } \\
\text { ortamın bilerek terk edilmesi }\end{array}$ & 96,7 & - & - & - & - & 3,3 \\
\hline $\begin{array}{l}\text { 33. İş arkadaşlarınızın sizinle konuşmasının } \\
\text { engellenmesi ya da yasaklanması }\end{array}$ & 96,7 & - & - & - & - & 3,3 \\
\hline
\end{tabular}

n=kişi sayısı, *0=hiç karşılaşmadım, 1=bir kez karşılaştım, 2=birkaç kez, 3=bazen, 4=sık sık, 5=her zaman karşılaşıyorum 
Tablo 2. İşte maruz kalınan psikolojik şiddet davranışlarının etkileri ( $\mathrm{n}=30)$

\begin{tabular}{|c|c|c|}
\hline & Evet $(\%)$ & Hayır $(\%)$ \\
\hline $\begin{array}{l}\text { 1. Bana yapılan düşmanca davranışları hatırladığımda şiddetli } \\
\text { üzüntü duyuyorum. }\end{array}$ & 10 & 90 \\
\hline 2. Yapılan davranışları tekrar tekrar hatırlıyorum/yaşıyorum & 10 & 90 \\
\hline İşe gelirken korkuyor, iş yerinde bulunmak istemiyorum & 6,7 & 93,3 \\
\hline Kendimi yalnız hissediyorum & 10 & 90 \\
\hline İş yerimde kimseye güvenmiyorum & 3,3 & 96,7 \\
\hline Kendime olan güvenim ve saygımın azaldığını hissediyorum & 0 & 100 \\
\hline $\begin{array}{l}\text { 7. İş dışındaki hayatım (evliliğim ve ailem) bundan olumsuz } \\
\text { olarak etkileniyor }\end{array}$ & 10 & 90 \\
\hline Çoğu zaman kendimi suçlu hissediyorum & 3,3 & 96,7 \\
\hline İçimden ağlama isteği geliyor & 6,7 & 93,3 \\
\hline Kendimi ihanete uğramış gibi hissediyorum & 6,7 & 93,3 \\
\hline $\begin{array}{l}\text { 11. Görünür bir neden yokken kötü bir şey olacakmış korkusu } \\
\text { yaşıyorum }\end{array}$ & 3,3 & 96,7 \\
\hline 12. Aşırı tedirginim ve kolayca ürküyorum & 3,3 & 96,7 \\
\hline Uyku düzenim bozuldu & 3,3 & 96,7 \\
\hline Kontrol dışı hareketlerim/tiklerim gelişti & 3,3 & 96,7 \\
\hline Kan basıncımda değişiklikler yaşıyorum & 3,3 & 96,7 \\
\hline Mide-bağırsak şikayetlerim oluyor & 3,3 & 96,7 \\
\hline Aşırı yemek yeme isteği ya da iştahta azalma oluyor & 3,3 & 96,7 \\
\hline Alkol, sigara ya da ilaç (madde) kullanımı & 6,7 & 93,3 \\
\hline Kendimi stresli ve yorgun hissediyorum & 16,7 & 83,3 \\
\hline Baş ağrilarım oluyor & 6,7 & 93,3 \\
\hline Depresyonda olduğumu düşünüyorum & 6,7 & 93,3 \\
\hline Göğüs ağrısı, kalp çarpıntısı oluyor & 3,3 & 96,7 \\
\hline $\begin{array}{l}\text { 23. Zamanımın büyük kısmını doğrudan işimle ilgili olmayan } \\
\text { konularla geçiriyorum }\end{array}$ & 3,3 & 96,7 \\
\hline 24. Hiçbir şey yapamadığım halde çok meşgul görüntüsü veriyorum & 3,3 & 96,7 \\
\hline 25. Bir şeyler yapılması gerektiğinde yavaş hareket ediyorum & 3,3 & 96,7 \\
\hline 26. İş ortamında çalışma arkadaşlarımla çatışma yaşıyorum & 6,7 & 93,3 \\
\hline Bir işe konsantre olmada güçlük yaşıyorum & 10 & 90 \\
\hline İ̀s yerindeyken hiçbir iş yapamıyorum & 0 & 100 \\
\hline İंşime karşı bağlılığımın azaldığını hissediyorum & 6,7 & 93,3 \\
\hline 30. İşle ilgili hatalar yapıyorum & 0 & 100 \\
\hline
\end{tabular}




\section{Tartışma}

Uluslararası Çalışma Örgütü' ne göre, birçok ülkede iş yerlerinde mobbing eylemlerinin bulunduğu belirtilmektedir (Chappell, Di Martino, 2000). Hacettepe Üniversitesi'nde çalışan engelli çalışanların işte maruz kaldıkları psikolojik şiddet davranışlarını ortaya koymak amacı ile yaptığımız araştırmada kişilerin büyük bir kısmının mobbing davranışıyla karşılaşmadığı tespit edilmiştir. Sayısının az olmasına rağmen kasten mobbing davranışları yaşayan engelli bireylerin olduğu saptanmıştır. Çalışmada dikkat çeken bir konu da, çalışmaya katılmaları için ulaşılan engelli bireylerden bir kısmının çalışmada gönüllü olarak bulunmak istememeleridir.

Çalışma ortamlarında mobbing davranışlarının sıklığını belirlemek üzere birçok ülkede, farklı çalışmalar yapılmıştır (Bilgel, Aytaç ve Bayram, 2006; Fox ve Stallworth, 2005; Björkqvist, Österman ve Hjelt-Back, 1994; Rutherford ve Rissel, 2004). Bu çalışmalarda katılımcıların iş yerinde mobbing davranışlarına maruz kalma oranları \%50 ile \%97 arasında değişiklik göstermekle beraber, bu mobbingin çoğunluğunun yönetim tarafından yapıldığ1 belirtilmiştir (Fox ve Stallworth, 2005; Rutherford ve Rissel, 2004). Lewis, işte karşılaşılan psikolojik şiddet ile ilgili akademisyenlerde gerçekleştirdiği çalışmada, kişilerin \%18'inin kasıtlı olarak bu davranışları yaşadığını ve bu sonucun, cins ayrımcılığı ve taciz oranlarından daha yüksek olduğunu söylemektedir (Lewis, 1999). Çalışmalar; kurum içerisinde ve kurumdaki kaynakların paylaşımında aşırı rekabetin olması, hiyerarşik yapılanma, kurumda ilerleme imkânlarının az olması, adaletsiz başarı değerlendirme, fazla iş yüklenmesi, ulaşımı zor olan amaçların bulunması, kurumlardaki psikolojik şiddet davranışlarına ortaya çıkaran etkenler olarak gösterilmektedir (Di Martino, Hoel ve Cooper, 2013; Salin, 2003). Çalışmamızda da bireyler kendilerine fazla iş verildiği ve olumsuz başarı değerlendirme gibi benzer durumlardan bahsetmişlerdir.

Çalışmamızda değerlendirmeye katılan engelli çalışanlar; psikolojik şiddet davranışları kapsamında gösterilen tutumları sürekli olarak hatırladıklarını veya yaşadıklarını, bu davranışları hatırladıklarında şiddetli üzüntü duyduklarını, iş yerinde bulunmak istemediklerini, iş dışındaki hayatlarının bundan olumsuz etkilendiğini, işe konsantre olmada güçlük çektiklerini, iş ortamındaki arkadaşlarıyla çatışma yaşadıklarını, işe karşı bağl1lıklarının azaldığını, kendilerini stresli ve yorgun hissettiklerini belirtmektedirler. Çalışmamıza katılan engelli personelin maruz kaldığ 1 mobbing durumunun kişilerde önemli etkiler yarattığı söylenebilir. $\mathrm{Bu}$ bağlamda kişilerin iş sırasında motivasyon kaybının 
önlenmesi amacıyla yönetici veya çalışma arkadaşları ile açık bir şekilde iletişim kurmanın, üniversiteye bağlı çalışan personel dairelerinin engelli bireylerin haklarına yönelik bilgilendirilmelerinin ve bu bireylerin çalışma yaşamındaki ihtiyaçlarından haberdar olmanın önemli olduğunu düşünmekteyiz. Aynı zamanda üniversite bünyesinde mobbing birimi kurulup, engelli çalışanlarda mobbingten kaynaklı etkileri minimuma indirebilecek çalışmalar yapılmasının mobbing davranışlarını önlemeye ve engelli bireylerin çalışma ortamlarının iyileştirilmesine katkıda bulunacağına inanmaktayız (Keim ve McDermott, 2010).

Mobbing ile ilgili yaptığımız bu çalışmada göz önünde bulundurulması gereken bir konu da çalışmaya katılmaya gönüllü olmak istemeyen bireylerin sayısıdır. Dâhil edilme kriterlerini sağlayan ve iletişime geçilebilen kırk engelli bireyden on kişi çalışmamıza katılmak istememiştir. Bu bireylerin özellikle araştırmanın konusu sebebiyle çalışmamıza katılmak istemediklerini düşünmekteyiz. $\mathrm{Bu}$ açıdan, katılım göstermeyen bireylerin de mobbinge maruz kalma ve iş kaybı korkusu yaşama ihtimalleri olabilmektedir. Bu sebeple çalışmaya katılmak istemeyen bireylerin göz ard1 edilmemesi gerektiğini ve bu bireylerin çalışmaya katılması dâhilinde sonuçlarımızın farklı olabileceğini düşünmekteyiz.

Çalışmamızda Mobbing ile Mücadele Derneği tarafından oluşturulan anket formu kullanılmıştır. $\mathrm{Bu}$ anket formunda bireylerin mobbinge maruz kalma davranışları ve bu davranışların etkisi sorgulanmıştır. Çalışmamızda bu yönüyle yapılandırılmış bir görüşme uygulanmıştır. Ancak görüşmeler sırasında bireylerin mobbing açısından önemli ifadelerde bulunduğu görülmüştür. Bundan dolayı bu bireylerin maruz kaldığı mobbinge yönelik daha kapsayıcı ve betimleyici sonuçlar elde etmek için ileriki çalışmalarda bu konu ile ilgili nitel araştırmaların planlanmasını önermekteyiz (Baillien, Neyens, Witte ve Cuyper, 2009; Efe ve Ayaz, 2010). 


\section{Kaynakça}

Baillien, E., Neyens, I., Witte, H. D., \& Cuyper, N. D. (2009). A qualitative study on the development of workplace bullying: Towards a three way model. Journal of Community \& Applied Social Psychology, 19(1), 1-16. doi:doi:10.1002/casp.977

Bilgel N., Aytaç S., Bayram N. (2006). Bullying in Turkish White-collar Workers. Occup Med, 56(4), 226-31.

Björkqvist K., Österman K., Hjelt-Back M. (1994). Agression Among University Employees. Agress Behav, 20(3), 173-84.

Björkqvist K. (2001). Social Defeat as a Stressor in Humans. Phsiol Behav, 73(3), 435-42.

Chappell D., Di Martino V. (2000). Understanding Violance at Work. ILO Report (2. Bask1). Geneva. Sf 3-24.

Davenport N., Schwartz R., Elliott GP. (2003). Mobbing: İş Yerinde Duygusal Taciz (1. Baskı). İstanbul: System Publishing, 66-71.

Di Martino V., Hoel H., Cooper C. (2003). Factor Contributing to Workplace Violance, Preventing Violance and Harassment in the Workplace (1. Bask1). Dublin: European Foundation for the Improvement of Living and Working Conditions, 13-22.

Efe, S. Y., \& Ayaz, S. (2010). Mobbing against nurses in the workplace in Turkey. International Nursing Review, 57(3), 328-334. doi:doi:10.1111/j.14667657.2010.00815.x

Einarsen S. (1996). Harassment and Bullying at Work: A review of the Scandinavian Approach. Agress Violent Behav, 5 (4), 379-401.

Einarsen S., Matthiesen S., Skogstad A. (1998). Bullying at Work: Bullying, Burnout and Well-being Among Assisstant Nurses. J Occup Health Safety, 14(6), 563-8.

Fox S., Stallworth L. E. (2005). Racial/Ethnic Bullying: Exploring Links Between Bullying and Racism in the US Workplace. J Vocat Behav, 66(3), 438-56.

Hansen A. M., Hogh A., Persson R., Karlson B., Garde A. H., Orbaek P. (2006). Bullying at Work, Health Outcomes, and Physiological Stress Response. J Psychosom Res, 60(1), 63-72.

Keim, J., \& McDermott, J. C. (2010). Mobbing: Workplace Violence in the Academy. The Educational Forum, 74(2), 167-173. doi:10.1080/00131721003608505

Lewis D. (1999). Workplace Bullying: Interim Findings of a Study in Further and Higher Education in Wales. Int J Manpower, 20(1/2), 106-19.

Leymann H. (1990). Mobbing and Psyscological Terror at Workplaces. Violance Vict, 5 (2), 119-26.

Leymann H. (1996). The Content and Development of Mobbing at Work. EJWOP, 5 (2), 165-84.

Leymann H., Gustafsson A. (1996). Mobbing at Work and the Development of Post-Traumatic Stress Disorders. EJWOP, 5 (2), 251-75.

Figueiredo-Ferraz, H., Gil-Monte, P. R., Grau-Alberola, E., Llorca-Pellicer, M., \& García-Juesas, J. A. (2012). Influence of Some Psychosocial Factors on Mobbing and its Consequences Among Employees Working with People with Intellectual Disabilities. Journal of Applied Research in Intellectual Disabilities, 25(5), 455-463. doi:doi:10.1111/j.1468-3148.2012.00687.x

Nielsen, M. B., Tangen, T., Idsoe, T., Matthiesen, S. B., \& Magerøy, N. (2015). Post-traumatic stress disorder as a consequence of bullying at work and at school. A literature review and metaanalysis. Aggression and Violent Behavior, 21, 17-24. doi:https://doi.org/10.1016/j.avb.2015.01.001

Quine L. (1999). Workplace Bullying in NHS Community Trust: Staff Questionnaire Survey. BMJ, 318(7178), 228-32.

Quine L. (2002). Workplce Bullying in Junior Doctors: Questionnaire Survey. BMJ, 324(7342), 878. 
Stebing J., Mandalia S., Portsmounth S., Leonard P., Crane J., Bower M. ve ark. (2004). A Questionnaire Survey of Stress and Bullying in Doctors Undertaking Research. Post Grad Med Journal, 80(940), 93-6.

Rutherford A., Rissel C. (2004). A Survey of Workplace Bullying in a Helath Sector Organisation. Aust Health Rev, 28(1), 65-72.

Salin D. (2003). Ways of Explaining Workplace Bullying: A review of Enabling, Motivating and Precipitating Structures and Processes in the Work Environment. Hum Relat, 56(10), 1213-32.

Salin D. (2003). Bullying and Organisational Politics in Competitive and Rapidly Changing Work Environments. IJMDM, 4(1), 35-46.

Tekin İ. (2006). Violance Against Emergency Staff. Türkiye Klinikleri J Surg Med Sci, 2(50), 68-73.

Tınaz P. (2006). İş Yerinde Psikolojik Taciz (1. Baskı). İstanbul: Beta Press, 7-17.

Tutar H. (2004). İş Yerinde Psikolojik Şiddet (3. Bask1). Ankara: BRC press, 9-16.

Yıldırım A., Yıldırım D. (2007). Mobbing in Nursing: Mobbing Experienced by Nurses Working in Health Care Facilities in Turkey and Its Effect on Nurses. J Clin Nurs, 16(8), 1445-53.

Yilmaz V. (2011). The Political Economy of Disability in Turkey: Disability and Social Policy Reform in Turkey. Almanya: LAP-Lambert Academic Publishing. 